\title{
Expression of angiotensin-converting enzyme 2 in CCL4-induced rat liver fibrosis
}

\author{
QIAN HUANG*, QING XIE*, CUI-CUI SHI, XIAO-GANG XIANG, LAN-YI LIN, \\ BANG-DONG GONG, GANG-DE ZHAO, HUI WANG and NI-NA JIA \\ Department of Infectious Disease, Ruijin Hospital, Shanghai Jiaotong \\ University School of Medicine, Shanghai 200025, P.R. China
}

Received January 12, 2009; Accepted March 3, 2009

\section{DOI: 10.3892/ijmm_00000185}

\begin{abstract}
The renin angiotensin system (RAS) plays a major role in liver fibrosis. A novel homologue of angiotensin converting enzyme, ACE2, was identified as a negative regulator of RAS as it degrades Ang II to Ang1-7. We investigated in vivo the expression of ACE2 in liver fibrosis. We evaluated the relationship between biochemical variables and liver tissue expression of ACE2, the correlation between a histological assessment of liver fibrosis and liver tissue expression of ACE2. Male SD rats were randomly divided into a CCL4 group which received injections of CCL4 and the control group which received injections of olive oil. Liver pathology was examined by H\&E and Sirius red staining, and real-time PCR was performed to determine the gene expression levels of ACE2 and ACE. Real-time PCR analysis revealed that ACE2 mRNA was higher at the two-, four-, and six-week time points, respectively $(\mathrm{p}<0.01)$. Similarly, hepatic ACE mRNA was significantly increased after CCL4 injection. There was a significant correlation between ACE and ACE2 gene expression $(\mathrm{r}=0.750, \mathrm{P}<0.001)$. ACE2 gene expression strongly correlated with ALT $(r=0.669, \mathrm{P}<0.0001)$ and AST levels $(r=0.815$, $\mathrm{P}<0.0001)$. There was a significant correlation between circulating ACE2 and histological scores of liver fibrosis. ACE2 and ACE gene expression correlated with the ISHAK score $(\mathrm{r}=0.850, \mathrm{P}<0.001 ; \mathrm{r}=0.806, \mathrm{P}<0.001)$. There was a significant relationship between ACE2 gene expression and the degree of liver fibrosis. ACE2 plays a crucial role in liver fibrogenesis.
\end{abstract}

\section{Introduction}

Liver fibrosis is a consequence of chronic liver injury of any etiology. The renin-angiotensin system (RAS) plays a major

Correspondence to: Dr Qing Xie, Department of Infectious Disease, Ruijin Hospital, Shanghai Jiaotong University School of Medicine, Shanghai 200025, P.R. China

E-mail: xieqingrj@yahoo.com.cn

${ }^{*}$ Contributed equally

Key words: angiotensin converting enzyme 2, angiotensin, liver fibrosis, angiotensin II role in liver fibrosis. Angiotensin converting enzyme (ACE), a dipeptidyl carboxypeptidase, is a key enzyme in RAS as it converts Ang I to the potent vasoconstrictor Angiotensin II (Ang II). Ang II mediates key biological actions involved in hepatic tissue repair, including myofibroblast proliferation, infiltration of inflammatory cells, and collagen synthesis (1-4). Importantly, blockage of RAS attenuates fibrosis development in different experimental models of chronic liver injury (5-9).

ACE2 is a recently identified homologue of ACE, which, unlike ACE, has only one active enzymatic site. It also degrades Ang II to Ang1-7 and cleaves a single residue from Ang I to generate Ang1-9 (10). Ang1-9 has no known effects, but is converted to Ang1-7 by ACE (11). There is evidence that Ang 1-7 modulates the effects of RAS activation through several mechanisms, including inhibition of ACE, blockage of the AT1 receptor, and a direct effect on vascular tone (12). Thus, ACE2 plays an important counterregulatory role to RAS. In experimental models of hypertension and diabetes, renal expression of this enzyme is reduced, which contributes to Ang II-mediated tissue injury $(13,14)$. ACE2 is also a functional receptor for the severe acute respiratory syndrome (SARS) coronavirus; therefore, it facilitates the infection of target cells $(15,16)$.

Paizis et al (17) recently reported that hepatic ACE2 expression is upregulated in cirrhotic human livers and in a rat BDL model. However, it is still unclear if these patterns of upregulation for ACE and ACE2 are specific to the BDL model. We suggest that expression of RAS in other models of experimental hepatic fibrosis warrants further investigation. The mechanism whereby the mRNA levels of ACE and ACE2 are sequentially modulated during hepatic fibrogenesis remains to be elucidated. In the current study, we aimed to examine expression of ACE and ACE2 in liver fibrosis induced by CCL4. Specifically, we evaluated the relationship between biochemical variables and liver tissue expression of ACE2, the association of histological assessment for liver fibrosis with liver tissue expression of ACE2, and the correlation between ACE and ACE2 gene expression.

\section{Materials and methods}

Animal model of liver fibrosis. Male Sprague-Dawly (SD) rats weighing 230-250 $\mathrm{g}$ were purchased from the Center of Animal Laboratory (SIBS, CAS) and maintained in a room at $23 \pm 2^{\circ} \mathrm{C}$ with a $12 \mathrm{~h}$ light-dark cycle. The rats were randomly 

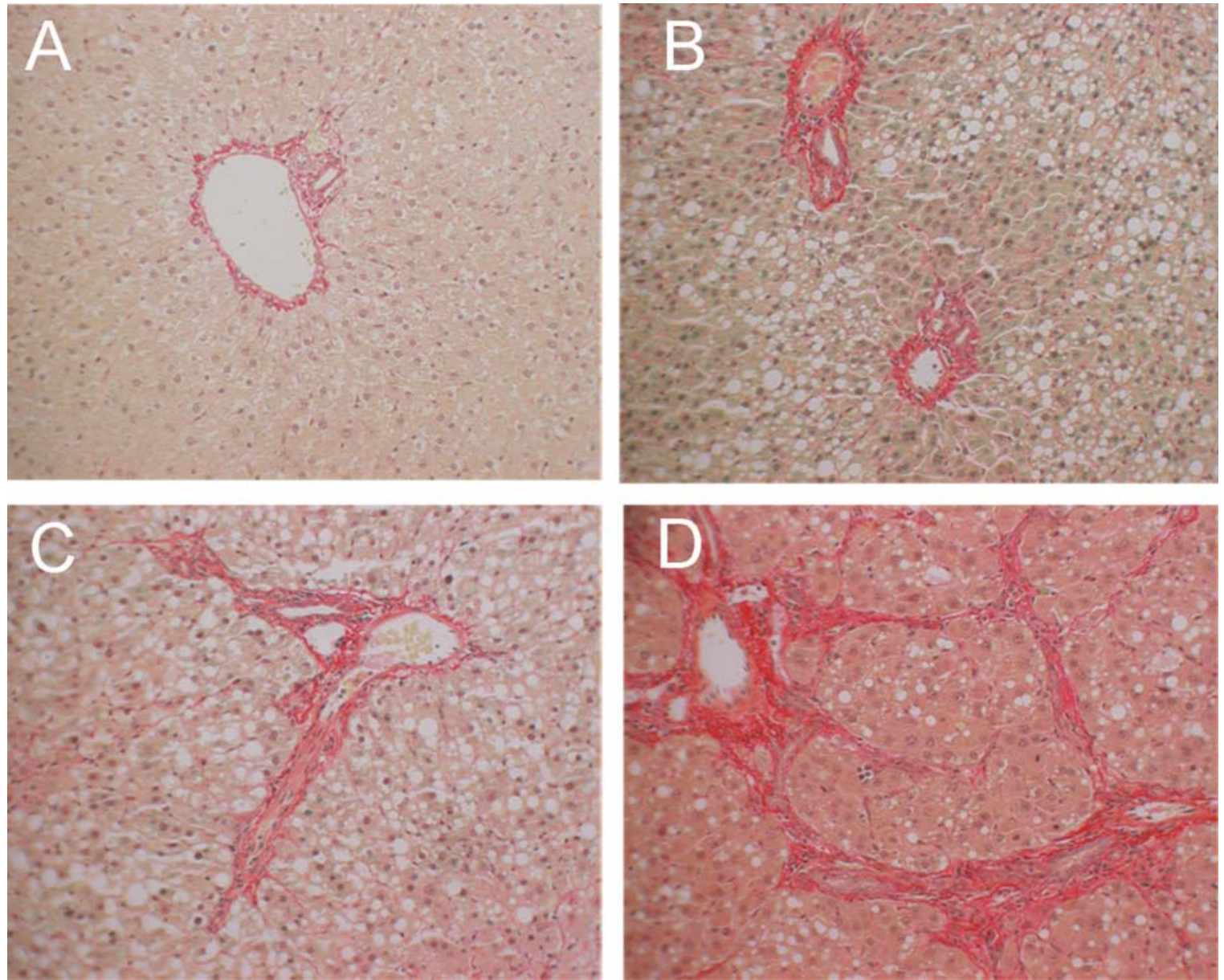

Figure 1. Representative microphotographs of the liver sections (Sirius red staining, original magnification, x200). (A) Control group with normal liver architecture and absence of fibrosis; (B) following injection of CCL4 at week 2 showing fibrous expansion of portal areas without short fibrous septa; (C) at week 4 exhibiting fibrous expansion of portal areas with portal-to-portal bridging; (D) at week 6 showing fibrous expansion of portal areas with marked portal-to-portal as well as portal-to-central bridging or occasional cirrhosis.

divided into two groups, the control group and experimental group ( $\mathrm{n}=8$ in each group). The experimental group received intraperitoneal injections of CCL4 $(2 \mathrm{ml} / \mathrm{kg})$ dissolved in olive oil (2:3 ratio) every three days for six consecutive weeks. The control group received intraperitoneal injections of olive oil ( $2 \mathrm{ml} / \mathrm{kg}$ ) every three days for six consecutive weeks. All procedures were approved by the Investigation and Ethics Committee and the Institutional Animal Care and Use Committee of Shanghai Jiaotong University School of Medicine.

\section{Experimental protocol}

Blood processing. Blood samples were obtained from the abdominal aorta. Serum was collected from the blood sample by immediate centrifugation at $4,000 \mathrm{x} \mathrm{g}$ for $10 \mathrm{~min}$ at $4^{\circ} \mathrm{C}$, and the serum was stored at $-70^{\circ} \mathrm{C}$. One set of sera was collected in tubes for measuring liver function. The second set of blood samples (supplemented with endopeptidase inhibitor 1-2 TIU/ml) was used to examine ACE2 levels.

Biochemical analysis. Serum alanine aminotransferase (ALT), aspartate aminotransferase (AST), bilirubin (TB), total protein (TP) and albumin (ALB) levels were measured by an autoanalyser (Beckman Instruments, Fullerton, CA, USA). Serum ACE2 levels were measured with an enzyme-linked
Table I. Primer sequences used for real-time PCR analysis.

\begin{tabular}{lc} 
Gene name & Primer sequences \\
\hline ACE2 & $\begin{array}{c}\text { sense CACCTTACGAGCCTCCTGTC } \\
\text { antisense TTTCGACCTTTGATCCCAGT } \\
\text { ACE }\end{array}$ \\
& sense ACGTCCCGGAAATACGAAG \\
antisense GCATCAGAGTAGCCGTTGAG & sense GACAACTTTGGCATCGTGGA \\
& antisense ATGCAGGGATGATGTTCTGG
\end{tabular}

immunosorbent assay (ELISA). The ACE2 antibody (sc-17720) was purchased from Santa Cruz (Santa Cruz, CA, USA).

Histological analysis. For histological analysis, sagittal liver sections were fixed with $4 \%$ buffered paraformaldehyde and embedded in paraffin. Sections of $2 \mu \mathrm{m}$ thickness were prepared and evaluated for liver fibrosis by $H \& E$ and Sirius red staining. The degree of fibrosis was measured by semiquantitative scoring, as described by Ishak et al (18). 
Table II. Liver function following injection of CCL4 in rats.

\begin{tabular}{lccrr}
\hline & week 0 & week 2 & week 4 & week 6 \\
\hline ALT & $40.5 \pm 2.204$ & $89.63 \pm 9.226$ & $217.9 \pm 142.4^{* *}$ & $225 \pm 150.6^{* *}$ \\
AST & $160.9 \pm 20.83$ & $206.1 \pm 48.66$ & $342.9 \pm 128.7^{*}$ & $536.6 \pm 209.2^{* *}$ \\
TBIL & $9.2 \pm 1.2$ & $12.04 \pm 3.219$ & $14.45 \pm 3.444^{*}$ & $18.34 \pm 7.429^{* *}$ \\
DBIL & $1.8 \pm 0.49$ & $3.188 \pm 1.254$ & $5.188 \pm 2.453^{*}$ & $7.8 \pm 4.708^{* *}$ \\
TP & $70.875 \pm 1.767$ & $77 \pm 6.99$ & $61.88 \pm 2.416^{*}$ & $56.5 \pm 1.852^{* *}$ \\
ALB & $16.5 \pm 2.07$ & $22.38 \pm 1.996^{*}$ & $16.88 \pm 1.126$ & $15.13 \pm 1.126$ \\
\hline
\end{tabular}

${ }^{*} \mathrm{P}<0.05,{ }^{* *} \mathrm{P}<0.01$, compared to week 0.
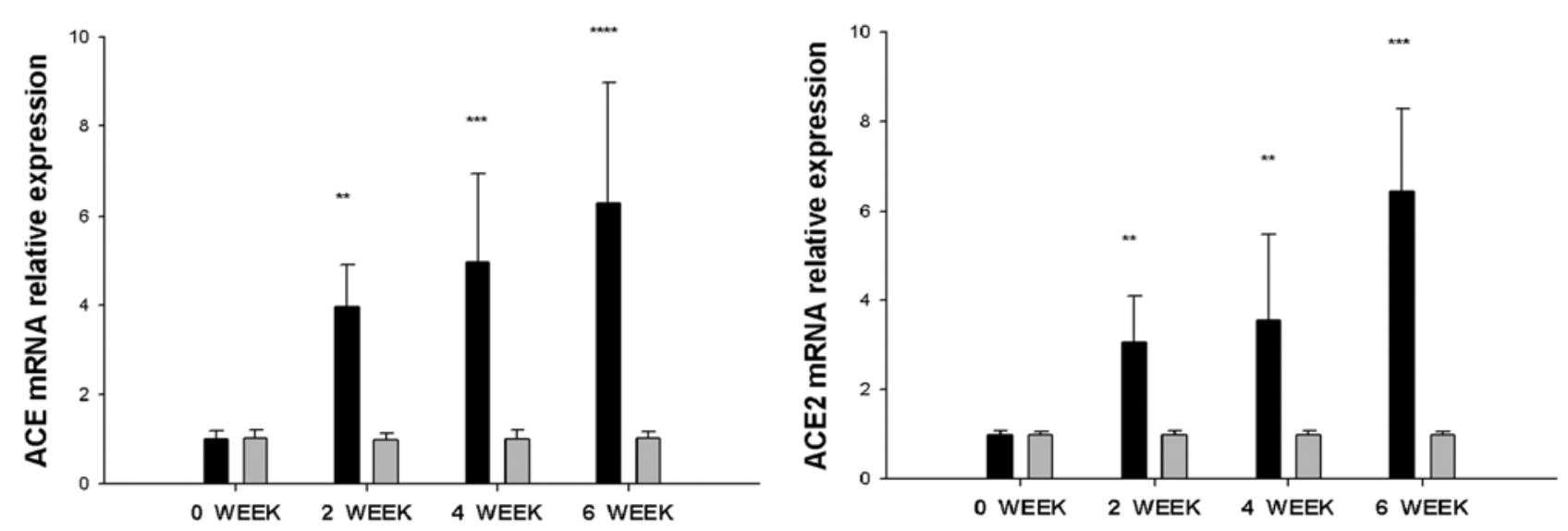

Figure 2. ACE and ACE2 mRNA expression in control (open bars) and experimental (filled bars) groups. QPCR-derived ACE2 gene expression levels were normalized to GAPDH, and the control groups were set at a value of one for each time point. ${ }^{* * *} \mathrm{P}<0.01,{ }^{* * *} \mathrm{P}<0.001$, experimental vs control.

Quantitative real-time polymerase chain reaction ( $Q P C R)$ analysis. Liver RNA expression levels for the genes reported in this study were quantified by real-time PCR. In brief, liver samples from a rat were snap-frozen in liquid nitrogen, and RNA was extracted using the TRIzol reagent (Invitrogen, Carlsbad, CA, USA). Total RNA $(1 \mu \mathrm{g})$ was reversetranscribed, and RNA expression levels were quantified by real-time PCR using a sequence detection system (Prism 7500; Applied Biosystems Inc., Foster City, CA, USA), as described previously. GAPDH served as the endogenous control. Primers for the reported genes are indicated in Table I. In order to calculate differences in the expression level of each target gene, the $\Delta \triangle \mathrm{CT}$ method for relative quantification was used according to the manufacturer's manual. The average expression level of the normal control samples were defined as one.

Western blot analysis. Liver tissue samples for Western blotting were homogenized in RIPA buffer $(20 \mathrm{mM}$ Tris $\mathrm{pH} 7.4$, 2.5 mM EDTA, 1\% Triton X-100, 10\% glycerol, 1\% deoxycholic acid, 0.1\% SDS, $1 \mathrm{mM}$ PMSF, $10 \mathrm{ng} / \mathrm{ml}$ aprotinin). Protein $(60 \mu \mathrm{g})$ was run by SDS-PAGE on a $10 \%$ gel, and the separated proteins transferred to nitrocellulose membranes. The blots were incubated in blocking buffer TBS-T (5\% nonfat milk, $0.1 \%$ Tween-20, in TBS) for $1 \mathrm{~h}$ at room temperature. The primary antibodies were then incubated overnight, and were washed 3 times for $10 \mathrm{~min}$ in TBS (containing $0.1 \%$
Tween-20). Membranes were incubated with a 1:2000 dilution of donkey anti-goat-HRP (Amersham Biosciences) in TBS with $0.1 \%$ Tween-20, 5\% nonfat milk for $1 \mathrm{~h}$, followed by washing as above and detection using the ECL Plus kit (Amersham Biosciences).

\section{Results}

Biochemistry and histological findings following CCL4 induction. Histological analysis showed either slight fibrosis (week 2) or extensive fibrosis (weeks 4 and 6) in the liver parenchyma following injection of CCL4 (Fig. 1). Serum AST, ALT, and bilirubin levels were significantly elevated in CCL4 group, compared with control group, $(\mathrm{P}<0.01$ to $\mathrm{P}<0.05$, Table II).

Changes in ACE2 and ACE gene expression in liver tissue. Injection of CCL4 resulted in significant changes in hepatic ACE2 gene expression, which progressively increased at weeks 2, 4, and 6 compared with control group. ACE2 expression increased in experimental group at weeks 2,4 , and 6 post-treatment to levels that were 3.08-, 3.57-, and 6.5-fold higher than controls, respectively $(\mathrm{P}=0.008, \mathrm{P}=0.001, \mathrm{P}<0.001)$. Similarly, hepatic ACE gene expression was significantly increased after injection of CCL4. Hepatic ACE gene expression was 3.93-fold higher after two weeks $(\mathrm{P}=0.002)$, and by 


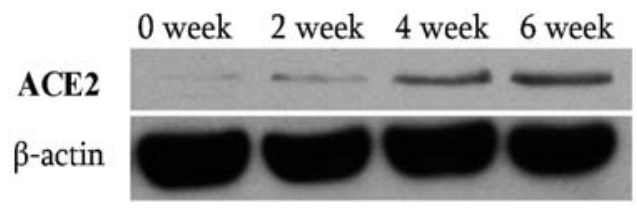

Figure 3. Western blot analysis of ACE2 protein levels in the liver tissue at various time points following CCL4 injection. $\beta$-actin is internal control.

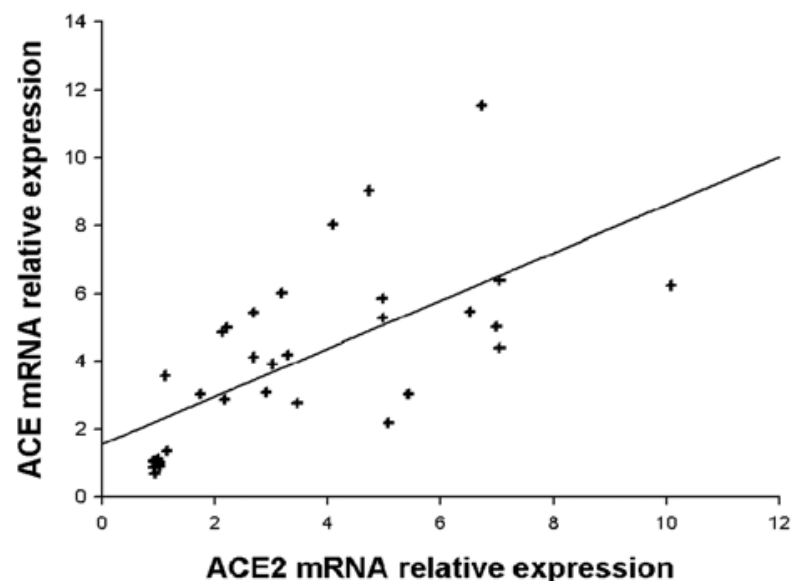

Figure 4. Relationship between ACE and ACE2 mRNA expression in liver tissues. The mRNA levels were adjusted as relative GAPDH mRNA values. Data are compared by Spearman's rank correlation coefficient; $r=0.750$, $\mathrm{p}<0.001$.

week 6, it had increased 6.23-fold compared with control group ( $\mathrm{P}<0.001$, Fig. 2).

Western blot analysis of ACE2 protein expression. Western blot analysis of ACE2 protein levels in the whole liver homogenates confirmed the measures of ACE2 mRNA levels. As in rat liver, ACE2 protein was detectable at very low levels in healthy livers. However, the ACE2 protein was induced after CCL4 injection and levels of this protein gradually increased.
ACE2 protein expression levels were significantly higher at weeks 2, 4, and 6 compared to week 0 (Fig. 3).

Relationship between ACE and ACE2 gene expression. We evaluated a potential correlation between ACE and ACE2 gene expression. This relationship is thought to be of interest because the two proteins have opposite effects on the generation of Ang II. Our data indicate that there is a significant correlation between ACE and ACE2 gene expression ( $\mathrm{r}=0.750$, $\mathrm{P}<0.001$, Fig. 4).

Biochemical variables and ACE or ACE2 gene expression. We assessed the relationship between biochemical variables and the gene expression of ACE or ACE2 in liver tissue. ACE2 gene expression strongly correlated with ALT ( $r=0.669$, $\mathrm{P}<0.0001)$ and AST levels $(\mathrm{r}=0.815, \mathrm{P}<0.0001$, Fig. 5). ACE had a moderate and statistically significant correlation with AST (r=0.475, P=0.006) and ALT (r=0.615, $\mathrm{P}<0.01$, Fig. 6). However, TP showed no significant correlation with ACE2 or ACE gene expression ( $\mathrm{r}=-0.088, \mathrm{P}=0.632 ; \mathrm{r}=0.138, \mathrm{P}=0.452)$.

Moreover, we evaluated the relationship between ACE2 (and ACE) gene expression and the histological assessment of liver fibrosis. Our findings suggest that ACE2 and ACE gene expression correlated with the ISHAK score $(\mathrm{r}=0.850$, $\mathrm{P}<0.001 ; \mathrm{r}=0.806, \mathrm{P}<0.001$, Fig. 7).

Circulating ACE2 level. The level of circulating ACE2 in the control group was $0.334 \pm 0.113(\mathrm{ng} / \mathrm{ml})$. Following injection of CCL4 its levels significantly and progressively increased at weeks 2,4 , and $6(0.564 \pm 0.332,0.816 \pm 0.338,0.934 \pm 0.462)$ compared with control group $(\mathrm{P}=0.006)$. There was a significant correlation between circulating ACE2 and liver fibrosis histological scores ( $\mathrm{r}=0.549, \mathrm{P}=0.001$, Fig. 8).

\section{Discussion}

A number of studies have provided evidence that RAS contributes to the pathogenesis of chronic liver disease. There is marked upregulation of intrahepatic RAS components in experimental injury, and RAS inhibitors were shown to
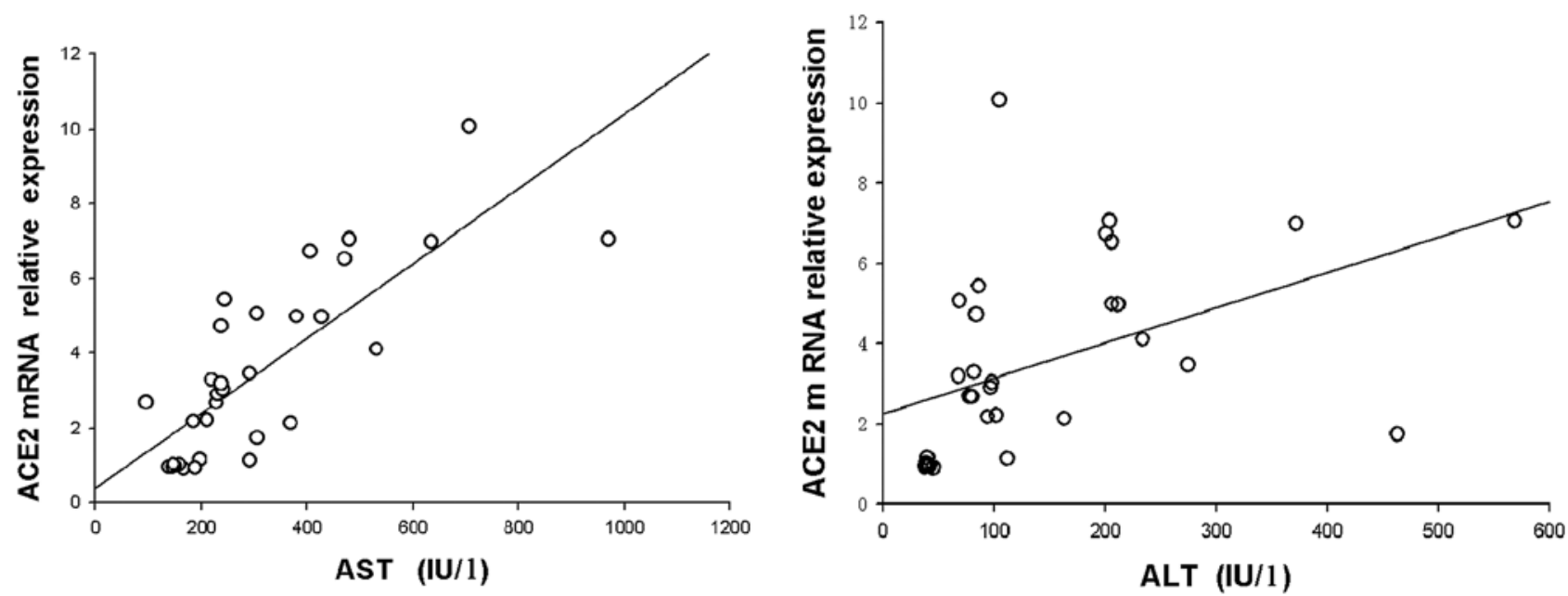

Figure 5. Relationship between hepatic ACE2 mRNA expression and ALT $(r=0.669, \mathrm{p}<0.0001)$ or AST $(\mathrm{r}=0.815$, p<0.0001). Data are compared by Spearman's rank correlation coefficient. 

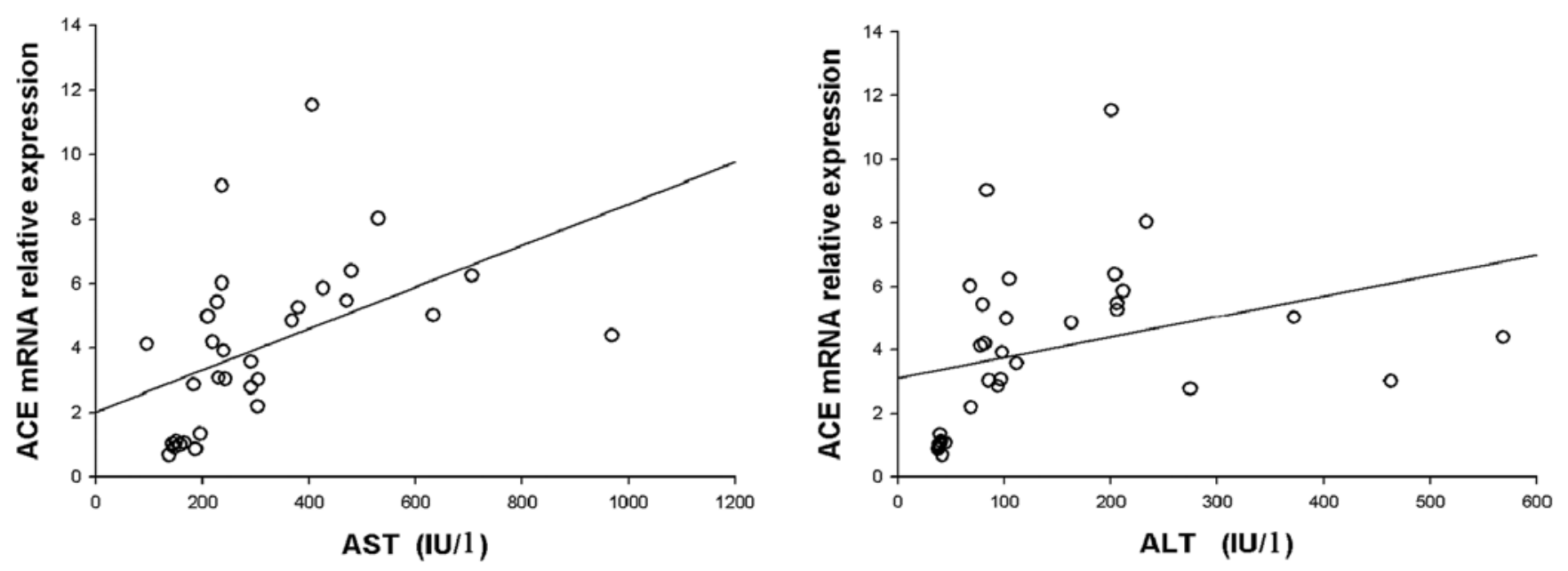

Figure 6. Relationship between hepatic ACE mRNA expression and ALT $(r=0.615, p<0.01)$ or AST $(r=0.475, p=0.006)$. Data are compared by Spearman's rank correlation coefficient.
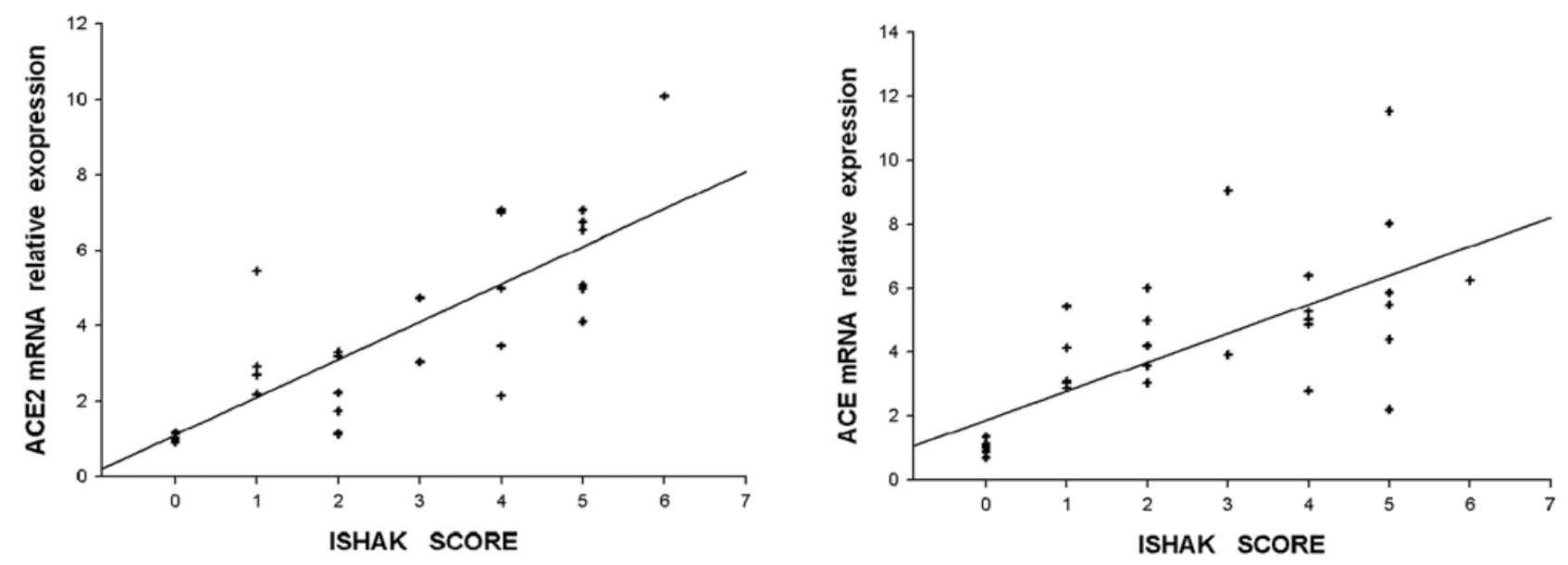

Figure 7. Relationship between hepatic ACE2 (and ACE) mRNA expression and ISHAK Score. Data are compared by Spearman's rank correlation coefficient; ACE2 ( $\mathrm{r}=0.850, \mathrm{P}<0.001), \mathrm{ACE}(\mathrm{r}=0.806, \mathrm{P}<0.001)$.

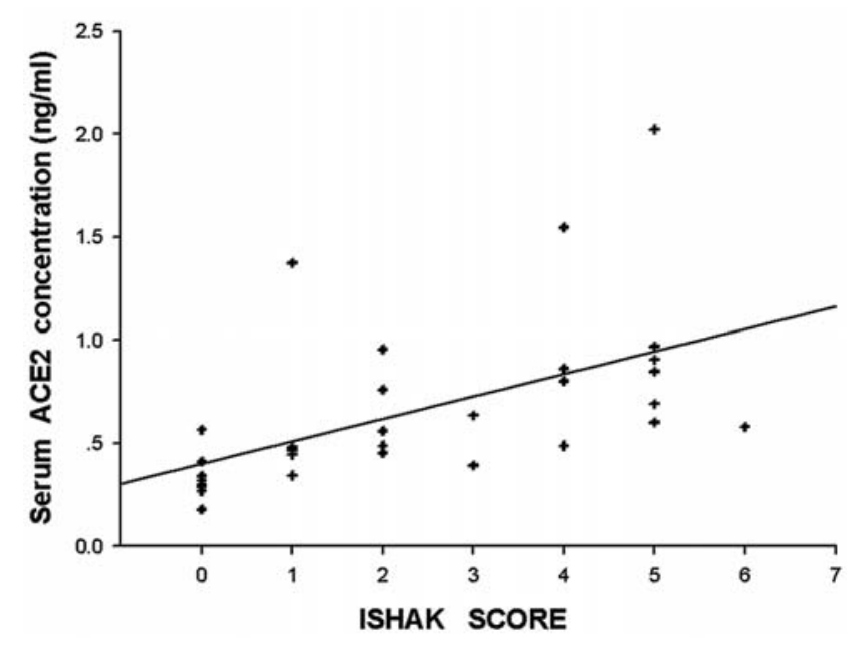

Figure 8. Relationship between the level of circulating ACE2 and ISHAK Score. Data are compared by Spearman's rank correlation coefficient; ACE2 $(\mathrm{r}=0.549, \mathrm{P}=0.001)$. reduce hepatic fibrosis in several animal models (19-21). Angiotensin converting enzyme (ACE), a dipeptidyl carboxypeptidase, is a key enzyme in RAS and converts Ang I to the potent vaso-constrictor Ang II. Recent discoveries identified ACE2 as an important enzyme that degrades Ang II and in turn generates Ang 1-7, which, by binding the G protein-coupled receptor Mas, acts as the main counterregulator of the traditional ACE-angiotensin II axis (22). Ang 1-7 was proposed to be the effector peptide that counterrbalances the deleterious actions of Ang II.

In vivo, ACE2 is predominantly expressed in the heart, kidneys, and testes. It is also present at a lower level in a wide variety of tissues, particularly the colon and lung $(23,24)$. Expression of ACE2 in normal human liver tissue is low $(23,25)$. Studies have shown that expression of ACE and ACE2 increased as rats developed advanced fibrosis. This finding is consistent with a previous study reported by Paizis et al (20). However, the work did not evaluate the relationship 
between ACE and ACE2 gene expression. The present study identified a close relationship between ACE and ACE2 mRNA levels in liver tissues. We consider this finding very important for elucidation of the mechanisms of interplay between ACE and ACE2 and for establishing the role of ACE2 as a counterregulator of ACE. Thus, we determined whether there was a correlation between the pathological grade of liver fibrosis and ACE2 mRNA levels in the liver. Our study shows that there is a significant relationship between the pathological grade of liver fibrosis and ACE2 mRNA levels in the liver. Furthermore, the level of hepatic ACE2 expression increased as liver fibrosis progressed.

ACE removes two carboxy-terminal amino acids from Ang I, giving rise to Ang II. Bataller et al (4) reported that systemic infusion of Ang II augments hepatic fibrosis and promotes inflammation, oxidative stress, and thrombogenic events in BDL rats. Furthermore, blockade of RAS by ACE inhibitors or angiotensin type 1 receptor antagonists significantly attenuates liver fibrosis $(6,19,26-29)$. In vitro, ACE2 degrades Ang II, generating Ang1-7. This pathway was also confirmed to exist in vivo (30). Ang1-7 is an endogenous ligand for the G-protein coupled receptor Mas, and the receptor appears to mediate most of the biological actions of Ang1-7 (31). Infusion of the selective Mas receptor antagonist, A-779, aggravated liver fibrosis, including a significant elevation in levels of tissue collagen and total TGFß1. These data suggest that Ang1-7 plays a protective role in hepatic liver fibrosis (32). The elevated activity of ACE2 during hepatic injury promotes Ang1-7 synthesis, which counterbalances the generation and multiple deleterious effects of Ang II. As ACE2 is capable of simultaneously degrading Ang II and generating Ang1-7, it clearly holds a central role in RAS. Studies have shown that systemic lentiviral delivery of ACE2 gene protects spontaneously hypertensive rats from Ang II-induced cardiac hypertrophy, cardiac fibrosis (33), and perivascular fibrosis (34). These studies suggest that ACE2 expression is a compensatory response to various insults in tissues. A cellular increase in ACE2 expression is regarded as a tissue-protective mechanism.

Moreover, the relationship between biochemical variables and the expression of ACE2 (or ACE) remains unclear. We first assessed the association between biochemical variables and the gene expression of ACE2 (or ACE) in liver tissue fibrosis. In the current study, the significant correlation between ALT level and expression of both genes were observed. Similar results were found in AST. There was no significant relationship between ACE2 gene expression in liver tissue and TBIL, TP, or ALB. The correlations between expression of ACE/ACE2 in the liver and liver function imply that the expression of RAS-related genes in the liver is related to the degree of liver damage. In fact, liver fibrosis is essentially a reparative response to liver injury and is the final pathological characteristic following various hepatic insults. This finding indirectly supports the hypothesis that ACE2 plays an important role in liver fibrogenesis.

ACE2 is a transmembrane protein that is shedded by the proteinase ADAM 17 to release free, circulating ACE2 (35). A role for circulating ACE2 is not yet identified. Our study demonstrated that there is a significant relationship between circulating ACE2 and the pathological grade of liver fibrosis.
There is a lack of useful serum markers for fibrosis in clinical practice. The results of this study imply that circulating ACE2 is a promising, non-invasive marker of liver fibrosis. The physiological implications and the possible clinical application of this marker require further study.

In conclusion, the mRNA levels of ACE and ACE2 were assessed to determine their relationship with biochemical characteristics of the liver. A significant association was observed between the expression of ACE and ACE2 in the liver. ACE2 and ACE gene expression also correlate significantly with the pathological grade of liver fibrosis. These findings suggest that, in addition to ACE, ACE2 is a newly emerging component of RAS that is likely to play an important role in maintaining a balanced status of local RAS activity. Thus, ACE2 exerts pivotal effects on liver fibrosis. In the future, development of specific modulators of ACE2 activity and function or an ACE2 inhibitor (36) would enable us to better understand the role of ACE2 in the pathophysiology of liver fibrosis.

\section{Acknowledgements}

This work was supported by a grant (07jc14044) from the Shanghai Science and Technology Association Development Foundation and by a grant (20070032) from the Liver Fibrosis Foundation of Wang Bao En.

\section{References}

1. Bataller R, Gines P, Nicolas JM, Gorbig MN, Garcia Ramallo E, Gasull X, Bosch J, Arroyo V and Rodes J: Angiotensin II induces contraction and proliferation of human hepatic stellate cells. Gastroenterology 118: 1149-1156, 2000.

2. Bataller R, Schwabe RF, Choi YH, Yang L, Paik YH, Lindquist J, Qian T, Schoonhoven R, Hagedorn CH, Lemasters JJ and Brenner DA: NADPH oxidase signal transduces angiotensin II in hepatic stellate cells and is critical in hepatic fibrosis. J Clin Invest 112: 1383-1394, 2003.

3. Yoshiji H, Kuriyama S, Yoshii J, Ikenaka Y, Noguchi R, Yanase K, Namisaki T, Yamazaki M, Tsujinoue H, Imazu H and Fukui H: Angiotensin-II induces the tissue inhibitor of metalloproteinases-1 through the protein kinase-C signaling pathway in rat liver fibrosis development. Hepatol Res 27: 51-56, 2003.

4. Bataller R, Gabele E, Parsons CJ, Morris T, Yang L, Schoonhoven R, Brenner DA and Rippe RA: Systemic infusion of angiotensin II exacerbates liver fibrosis in bile duct ligated rats. Hepatology 41: 1046-1055, 2005.

5. Croquet V, Moal F, Veal N, Wang J, Oberti F, Roux J, Vuillemin E, et al: Hemodynamic and antifibrotic effects of losartan in rats with liver fibrosis and/or portal hypertension. J Hepatol 37: 773-780, 2002.

6. Jonsson JR, Clouston AD, Ando Y, Kelemen LI, Horn MJ, Adamson MD, Purdie DM and Powell EE: Angiotensin converting enzyme inhibition attenuates the progression of rat hepatic fibrosis. Gastroenterology 121: 148-155, 2001.

7. Kurikawa N, Suga M, Kuroda S, Yamada K and Ishikawa H: An angiotensin II type 1 receptor antagonist, olmesartan medoxomil, improves experimental liver fibrosis by suppression of proliferation and collagen synthesis in activated hepatic stellate cells. Br J Pharmacol 139: 1085-1094, 2003.

8. Yang L, Bataller R, Dulyx J, Coffman TM, Gines P, Rippe RA and Brenner DA: Attenuated hepatic inflammation and fibrosis in angiotensin type 1a receptor deficient mice. J Hepatol 43: 317-323, 2005.

9. Yoshiji H, Kuriyama S, Yoshii J, Ikenaka Y, Noguchi R, Nakatani T, Tsujinoue $\mathrm{H}$ and Fukui $\mathrm{H}$ : Angiotensin-II type 1 receptor interaction is a major regulator for liver fibrosis development in rats. Hepatology 34: 745-750, 2001.

10. Ferrario CM, Chappell MC, Tallant EA, et al: Counterregulatory actions of angiotensin-(1-7). Hypertension 30: 535-541, 1997. 
11. Burrell LM, Johnston CI, Tikellis C, et al: ACE2, a new regulator of the rennin angiotensin system. Trends Endocrinol Metab 15: 166-169, 2004.

12. Yagil Y and Yagil C: Hypothesis: ACE2 modulates blood pressure in the mammalian organism. Hypertension 41: 871-873, 2003.

13. Crackower MA, Sarao R, Oudit GY, et al: Angiotensinconverting enzyme 2 is an essential regulator of heart function. Nature 417: 822-828, 2002

14. Tikellis C, Johnston CI, Forbes J, et al: Characterisation of renal angiotensin converting enzyme 2 in diabetic nephropathy. Hypertension 41: 392-397, 2003.

15. Li W, Moore MJ, Vasilieva N, et al: Angiotensin-converting enzyme 2 is a functional receptor for the SARS coronavirus Nature 426: 450-454, 2003.

16. Dimitrov DS: The secret life of ACE2 as a receptor for the SARS virus. Cell 115: 652-653, 2003.

17. Paizis G, Tikellis C, Cooper ME, Schembri JM, Lew RA, Smith AI, et al: Chronic liver injury in rats and humans upregulates the novel enzyme angiotensin converting enzyme 2. Gut 54: 1790-1796, 2005.

18. Ishak K, Baptista A, Bianchi L, Callea F, De Grote J, Gudat F et al: Histologic grading and staging of chronic hepatitis. Hepatol 22: 696-699, 1995.

19. Paizis G, Gilbert RE, Cooper ME, et al: Effect of angiotensin II type 1 receptor blockade on experimental hepatic fibrogenesis. J Hepatol 35: 376-385, 2001.

20. Paizis G, Cooper ME, Schembri JM, et al: Up-regulation of components of the renin-angiotensin system in the bile ductligated rat liver. Gastroenterology 123: 1667-1676, 2002.

21. Bataller R, Sancho-Bru P, Gines P, et al: Activated human hepatic stellate cells express the renin-angiotensin system and synthesize angiotensin II. Gastroenterology 125: 117-125 2003.

22. Santos RAS, Simo es e Silva AC, Maric C, Silva DMR, Machado RP, Buhr I, et al: Angiotensin-(1-7) is an endogenous ligand for the G-protein coupled receptor Mas. Proc Natl Acad Sci USA 100: 8258-8263, 2003.

23. Donoghue M, Hsieh F, Baronas E, et al: A novel angiotensinconverting enzyme-related carboxypeptidase (ACE2) converts angiotensin I to angiotensin 1-9. Circ Res 87: E1-E9, 2002.

24. Tipnis SR, Hooper NM, Hyde R, Karran E, Christie G and Turner AJ: A human homolog of angiotensin-converting enzyme: loning and functional expression as a captoprilinsensitive carboxypeptidase. J Biol Chem 275: 33238-33243, 2000 .

25. Harmer D, Gilbert M, Borman R, et al: Quantitative mRNA expression profiling of ACE 2, a novel homologue of angiotensin converting enzyme. FEBS Lett 532: 107-110, 2002
26. Lee JK, Hsieh JF, Tsai SC, Ho YJ and Kao CH: Effects of single dose of $50 \mathrm{mg}$ captopril in patients with liver cirrhosis and ascitis. Hepato-Gastroenterology 47: 767-770, 2000.

27. Yoshiji H, Yoshii J, Ikenaka Y, Noguchi R, Tsujinoue H, Nakatani T, Imazu H, Yanase K, Kuriyama $\mathrm{S}$ and Fukui $\mathrm{H}$ : Inhibition of renin-angiotensin system attenuates liver enzymealtered preneoplastic lesions and fibrosis development in rats. J Hepatol 37: 22-30, 2002

28. Terui Y, Saito T, Watanabe H, Togashi H, Kawata S, Kamada Y and Sakuta $\mathrm{S}$ : Effect of angiotensin receptor antagonist on liver fibrosis in early stages of chronic hepatitis C. Hepatology 36: 1022, 2002

29. Ohishi T, Saito H, Tsusaka K, Toda K, Inagaki H, Hamada Y, Kumagai N, Atsukawa K and Ishii H: Anti-fibrogenic effect of an angiotensin converting enzyme inhibitor on chronic carbon tetrachloride-induced hepatic fibrosis in rats. Hepatol Res 21: 147-158, 2001.

30. Zisman LS, Meixell GE, Bristow MR and Canver CC: Angiotensin-(1-7) formation in the intact human heart: in vivo dependence on angiotensin II as substrate. Circulation 108: 1679-1681, 2003

31. Santos RA and Ferreira AJ: Angiotensin-(1-7) and the rennin angiotensin system. Curr Opin Nephrol Hypertens 16: 122-128, 2007

32. Pereira RM, Dos Santos RA, Teixeira MM, et al: The reninangiotensin system in a rat model of hepatic fibrosis: evidence for a protective role of Angiotensin1-7. J Hepatol 46: 674-681, 2007.

33. Huentelman MJ, Grobe JL, Vazquez J, et al: Protection from angiotensin II-induced cardiac hypertrophy and fibrosis by systemic lentiviral delivery of ACE2 in rats. Exp Physiol 90: 783-790, 2005

34. Diez-Freire C, Vazquez J, Correa de Adjounian MF, et al: ACE2 gene transfer attenuates hypertension linked pathophysiological changes in the SHR. Physiol Genomics 27: 12-19, 2006.

35. Lambert DW, Yarski M, Warner FJ, Thornhill P, Parkin ET, Smith AI, et al: Tumor necrosis factor-alpha convertase (ADAM17) mediates regulated ectodomain shedding of the severe-acute respiratory syndrome-coronavirus (SARS-CoV) receptor, angiotensin-converting enzyme-2 (ACE2). J Biol Chem 280: 30113-30119, 2005

36. Dales NA, Gould AE, Brown JA, et al: Substrate-based design of the first class of angiotensin converting enzyme-related carboxypeptidase (ACE2) inhibitors. J Am Chem Soc 124 $11852-11853,2002$. 